anales de psicología, 2018, vol. 34, $\mathrm{n}^{\circ} 1$ (january), 135-145 http://dx.doi.org/10.6018/analesps.34.1.232901
(C) Copyright 2018: Editum. Servicio de Publicaciones de la Universidad de Murcia. Murcia (Spain) ISSN print edition: 0212-9728. ISSN web edition (http://revistas.um.es/analesps): 1695-2294

\title{
Psychometric Properties of the Inventory of Beliefs about Intimate Partner Violence (IBIPV)
}

\author{
Cristina García-Ael*, Patricia Recio, and Prado Silván-Ferrero
}

Universidad Nacional de Educación a Distancia (UNED) (Spain).

\begin{abstract}
Título: Propiedades psicométricas del inventario de creencias sobre violencia de pareja íntima.

Resumen: Este estudio analiza las propiedades psicométricas del Inventario de Creencias sobre la violencia de pareja. En concreto, este inventario mide actitudes generales y específicas hacia la violencia contra las mujeres dentro de las relaciones de pareja. En el estudio participan 1169 personas con una edad comprendida entre 18 y 77 años. Los resultados muestran tres factores: a) Justificación de la violencia de género, b) Responsabilidad de la víctima y c) Responsabilidad del maltratador. El análisis factorial confirmatorio mostró índices de ajuste apropiados: $\mathrm{CFI}=.952, \mathrm{NFI}=.942 \mathrm{y}$ RMSEA $=.062(90 \%$ CI [.058 - .065]). Además, los resultados muestran validez convergente y divergente con el sexismo ambivalente hacia las mujeres y hacia los hombres. Se discute la utilidad de esta escala en el ámbito de la violencia contra la pareja.
\end{abstract}

Palabras clave: Actitudes; Violencia contra la pareja; Sexismo; Género.

\section{Introduction}

Intimate partner violence (IPV) is a serious social problem affecting all countries, cultures and social levels. IPV is defined as a range of physical, psychological and sexual coercive behaviours, carried out against women by a partner or ex-partner (Organización de Naciones Unidas, ONU, 2006). Unlike other types of gender violence, (e. g., sexual abuse or harassment at work), IPV is classified as a serious form of violence due to its high prevalence, mortality and effects on women's physical and mental health (Organización Mundial de la Salud, OMS, 2005). In recent years various instruments have been developed for estimating the prevalence of IPV (CTS2, The Revised Conflict Tactics Scale, Straus, Hamby, Boney-McCoy, \& Sugarman, 1996) and assessing endorsement of myths about IPV (Peters, 2008); however there was been less research on beliefs about IPV. This study analysed the psychometric properties of the Inventory of Beliefs about Intimate Partner Violence (IBIPV), an inventory that measures general and specific attitudes to violence against women in intimate partnerships.

\section{Attitudes to and Beliefs about IPV}

Attitudes to IPV not only indicate its prevalence in our society, but are also a key to understanding how people behave towards victims and perpetrators of IPV (Gracia, García, \& Lila, 2009). There is a large amount of studies on this topic (for a review see, Waltermaurer, 2012). However, research has focused principally on justifications for IPV, vic-

* Correspondence address [Dirección para correspondencia]: Cristina García-Ael. Departamento de Psicología Social y de las Organizaciones. Facultad de Psicología (UNED). Juan del Rosal, No 10, 28040 Madrid (Spain). E-Mail: cgarciaael@psi.uned.es

\begin{abstract}
This study analysed the psychometric properties of the Inventory of Beliefs about Intimate Partner Violence (IBIPV) which is designed to measure general and specific attitudes to violence against women in intimate relationships. The participants were 1169 people aged from 18 to 77 years. We found that the IBIPV has a three-factor structure, the factors identified were: a) Justifying Partner Violence (JPV), b) Victims Responsible for Violence (VRV) and c) Abuser Responsible for Violence (ARV). Multi-group confirmatory factor analysis showed three levels of measurement invariance across gender: configural, metric and scalar invariance. As expected, evidence of the convergent and divergent validity of the inventory was provided by comparisons with the Ambivalent Sexism Inventory (ASI) and Ambivalence toward Men Inventory (AMI). Potential applications of the scale in the field of partner violence are discussed.
\end{abstract}

Keywords: Attitudes; Intimate Partner Violence; Sexism; Gender. tim blaming and exoneration of perpetrators (e.g. Gracia, García, \& Lila, 2014). Justifications of the IPV and the belief that IPV is acceptable are associated with victim blaming (West \& Wandrei, 2002). In particular, people tend to consider IPV acceptable when victims behave in a provocative way (Gracia \& Herrero, 2006b) or when IPV is perceived as less severe and less frequent (Gracia \& Herrero, 2006a). Victim-blaming attitudes are also related to the exoneration of perpetrators (Gracia, 2014; Gracia \& Herrero, 2006b; ValorSegura, Expósito, \& Moya, 2011). For example, Valor-Segura et al. (2011) reported that people are more likely to blame the victim and exonerate the perpetrator if the cause of IPV is not mentioned (in their study the cause was visiting an old, male friend). Other studies have also found that factors such as knowing women victims of IPV in the circle of friends and family may increase the likelihood of victim-blaming attitudes (Gracia \& Tomás, 2014). However, there is a broad consensus among researchers that the strongest determinants of attitudes to IPV are gender and traditional beliefs about gender roles (e.g., Berkel, Vandiver, \& Bahner, 2004; Ferrer, Bosch, Ramis, \& Navarro, 2006; Flood \& Pease, 2009).

With a few exceptions (e.g., Gracia \& Tomas, 2014), studies tend to show that men and women differ in their attitudes to or judgements of IPV. For example, women tend to express stronger disapproval of IPV (Sakalli, 2001) and to hold more lenient attitudes toward IPV victims than men (Alfredsson, Ask, \& Borgstede, 2016; LanghinrichsenRohling, Shlien-Dellinger, Huss, \& Kramer, 2004) whereas men are more likely to agree with myths about IPV (Ferrer et al., 2006; Flood \& Pease, 2009) and tend to excuse the abuser's aggressive behaviour and blame victim more than women (Valor-Segura, Expósito, \& Moya, 2008; 2011).

Traditional gender stereotypes (men as breadwinners; women as housewives and mothers) and sexist beliefs also have a great influence on people's explanations for IPV (e.g., 
Cantera \& Blanch, 2010; Valor-Segura et al., 2011). A vast number of studies have revealed that people with traditional beliefs about gender roles are more likely to endorse justifications of IPV than people with egalitarian beliefs (e.g., Yamawaki, Ochoa-Shipp, Pulsipher, Harlos, \& Swindler, 2012). Regarding sexist beliefs, hostile sexism (legitimisation of violence against women challenging the power of men) supports the justification of IPV, victim blaming and exonerating perpetrators (Glick, Sakalli-Ugurlu, Ferreira, \& de Souza, 2002; Sakalli, 2001). So-called benevolent sexism also considers IPV legitimate when women do not fulfil their traditional roles (Glick et al., 2002; Valor-Segura et al., 2008; Valor-Segura et al., 2011).

Other socio-demographic factors such as age are also associated with a higher likelihood of acceptance of IPV. For example, some studies have found that people over 55 years old are more likely to blame the victims of IPV than middleaged people. Similarly, Gracia et al. (2009) found that scenarios were perceived less severe by old people than by middleaged people, and old people also felt less personally responsible to help in cases of IPV.

In summary, research has shown that attitudes to IPV are a social phenomenon with a complex aetiology based on role expectations, socio-cultural norms, socio-demographic factors that support female subordination and male violence (American Psychological Association, 1996).

\section{Measuring Attitudes to IPV}

Research on attitudes to IPV has resulted in the creation of a great variety of evaluation instruments, many are ad hoc instruments developed to meet the needs of particular research projects (Valor-Segura et al., 2008) and in some cases their metric qualities have not been evaluated (Pueyo, López, \& Álvarez, 2008). However, there are reliable instruments for which psychometric are available, these include the Inventory of Beliefs about Wife Beating (IBWB, Saunders, Lynch, Grayson, \& Linz, 1987), the Domestic Violence Myth Acceptance Scale (Peters, 2008) and the Intimate Partner Violence Responsibility Attribution Scale (IPVRAS, Lila, Oliver, Catalá-Miñana, Galiana, \& Gracia, 2014). Of the instruments mentioned, the IBWB is the only one designed to assess general and specific attitudes towards domestic violence; the DVMAS assesses perceptions of myths about domestic violence (Peters, 2008) and the IPVRAS assesses perpetrators' attributions of responsibility for IPV.

The IBWB (Saunders et al., 1987) is an inventory of beliefs about wife beating, developed from various scales measuring popular beliefs about domestic violence and attitudes towards rape victims as well as interviews with battered women and shelter managers. The 30-item scale is organised into five subscales. The WJ subscale (Wife beating is justified; 12 items) contains items that reflect the attitude that wife beating is generally justified. The WG subscale (Wives gain from beatings; 7 items) is related to beliefs that blame wife beating on women's provocative or even masochistic behaviour. The
HG subscale (Help should be given, 5 items) refers to the desirability of bystanders' taking personal action when battered women are attacked. The OP subscale (Offender should be punished; 5 items) includes items that urge the immediate separation of the couple, through the woman's departure or through the jailing of the abuser. Finally, the OR subscale (Offender is responsible; 4 items) assesses general attribution of intentionality to the abuser and attitude to the jailing of abusers. In general terms the IBWB is highly reliable there is evidence that test scores are valid. All the dimensions are associated with traditional attitudes to gender roles and with an explicit hostility to women (convergent validity). Evidence for the differential validity of the scale has also been found in students and people involved in or dealing with partner violence, such as victims, lawyers and abusers.

The IBWB does, however, have some limitations. Firstly, it only assesses attitudes to domestic violence perpetrated on married women (Peters, 2008). In addition, three of its scales have low internal reliability (HG, OP and OR between .61 and .67, Saunders et al., 1987). Finally, the sample is made up not only of general population (students), but also of different sub-samples that differ greatly from each other's (e.g., abusers, advocates for battered women, nurses, physicians).

Despite these limitations, the IBWB has been applied in Western countries such as the United States and Spain (Craig, Robyak, Torosian, \& Hummer, 2006; Expósito \& Ruiz, 2010), in Arab countries (e.g., Haj-Yahia \& de Zoysa, 2007) and in cross cultural comparisons (Glick et al., 2002). Haj-Yahia (2003) revised and adapted the IBWB for used in the Arab context, introducing new items and Craig et al. (2006) developed the IBAPA (Inventory of Beliefs about Partner Abuse), an inventory that replaces some expressions in the IBWB with expressions that are more in line with current terminology (e.g. 'wife' with 'partner' and 'beating with 'abuse').

The most important contributions of these IBWB revisions include the following: a) a redistribution of items of the WJ and WG scales; b) the development of a scale assessing attribution of responsibility to the victim; c) the addition of new items to the scale assessing attribution of responsibility to the abuser (Haj-Yahia, 2003); and d) the adjustment of terminology so that the items also cover domestic violence against women who are not married to the perpetrator (Craig et al., 2006).

Although these revisions represent substantial development of the original IBWB, they still suffer from two important deficiencies which make further revision necessary. Firstly, there are data on the reliability of the various subscales of the adaptations, but no data on their validity. The original inventory (IBWB) seems to be the only instrument for which the psychometric properties are known.

Secondly, the revisions of the IBWB have failed to take account of some of the theoretical and empirical developments in this field. For example, various studies have confirmed that the most prevalent form of IPV is psychological abuse (e.g., Cappezza \& Arriga, 2008; Rathus \& Feindler, 
2004), yet none of these scales include references to more subtle abuse such as systematic and persistent denigration or humiliation aimed at controlling the partner (Buesa \& Calvete, 2011) or representations of other factors such as partner conflicts (Maiuro, 2004) or the economic (in)dependence of the woman (Stith, Smith, Penn, Ward, \& Tritt, 2004).

Finally, the original and the various adaptations cover a wide range of factors which complicates the task of producing an operational definition of the construct and accordingly limits its accuracy (Buesa \& Calvete, 2011). Moreover, some of the subscales are insufficiently developed (e.g., Offenders should be punished, OP, or Help should be given: OR). For example, recent research has analyzed (amongst other issues) the effects of feeling a sense of personal responsibility to act in cases of IPV using hypothetical scenarios that differ in severity of the violence (e.g. 'A women is often verbally abused and humiliated by her partner') (Gracia et al., 2009). Several studies have used only certain subscales of the IBWB (Gracia, Rodriguez, \& Lila, 2015).

The broad aim of this study was, therefore, to revise, update and recast the IBWB to take into account the latest theoretical and empirical advances in the field and to evaluate the properties of the new instrument using more advanced statistical techniques such as confirmatory factor analysis. After developing the new instrument, we first confirmed its dimensional structure. Next, we assessed its convergent validity by examining its relationship with sexism using the(Ambivalent Sexism Inventory, ASI, Glick \& Fiske, 1996), the most widely employed instrument this field, and the (Ambivalent Toward Men Inventory, AMI, Glick \& Fiske, 1999), which has never been used to measure attitudes to IPV. Finally, we assessed its differential validity using participants' gender and age as variables.

\section{Method}

\section{Participants}

The sample consisted of 1169 Spanish participants (49.4\% men and 50.6\% women) with work experience, ranging from 18 to 77 years $(M=40.13 ; S D=11.17)$ and varying in parental status $(n$ single $=499, n$ married $=571, n$ widowed $=15$, $n$ divorced $=101)$. Forty-seven per cent had received higher education $(n=562)$ and the maximum level of education achieved by the remainder was distributed as follows, primary school: $n=143$; secondary school: $n=272$; vocational education: $n=144$. Just over half $(51.9 \%, n=621)$ were in permanent employment and the employment status of the remainder was distributed as follows, temporary contract: $n$ =168; unemployment: $n=190$; self-employment: $n=103$; retired: $n=44$. Finally, almost all Spanish Autonomous Regions were represented in the sample, the exceptions were La Rioja and Ceuta ( $n_{\text {Galicia }}=97, n$ País Vasco $=30, n$ Comunidad Valenciana $=146, n$ Castilla-León $=50, n_{\text {Islas Baleares }}=18, n_{\text {Extremadura }}=$ $25, n_{\text {Andalucía }}=172, n_{\text {Castilla La Mancha }}=37, n_{\text {Canarias }}=60, n_{\text {Madrid }}$

$$
\begin{aligned}
& =266, n_{\text {Aragón }}=31, n \text { Principado de Asturias }=10, n_{\text {Cataluña }}=70, n \\
& \text { Murcia } \left.=11, n_{\text {Navarra }}=10, n_{\text {Cantabria }}=17, n_{\text {Melilla }}=2\right) \text {. }
\end{aligned}
$$

\section{Procedure}

Data were collected over a one-year period. The sample was an incidental sample. Students from the National University of Distance Education doing their final courses in Psychology and Social Work who participated in the investigation in exchange for practical credits. The research team provided them with a set of standard instructions to ensure that all participants completed the questionnaires under the same conditions (Morgan, Krueger, \& King, 1998).

First students had to complete the questionnaire themselves. Then, they had to recruit other participants and inform them about the goals of research by e-mail (and remainder mailing). The recruitment procedure was carried out entirely online. Participants completed the registration page and the consent form first and then filled out the questionnaire. The order in which the subscales were presented was counterbalanced. All participants were guaranteed anonymity and confidentiality. To avoid bias and repeated participation, psychology students and other participants who did not provide personal data or failed to complete the consent form and multiple responses from the same IP were removed from the database (response rate $=86.59 \%$ ).

\section{Instrument}

Inventory of Beliefs about Intimate Partner Violence (IBIPV). As a preliminary step, Spanish versions of the IBWB items were produced by blind back-translation (Jackson, Guthrie, Astilla, \& Elwood, 1983). Two experts in methodology and two experts in gender violence evaluated the original scale and the final translated version methodologically and substantively (Balluerka, Gorostiaga, AlonsoArbiol, \& Haranburu, 2007). Items were excluded if a) they had nothing to do with beliefs about IPV (5 items from the HG subscale); b) IPV was linked to a masochistic image of the woman ( 2 items from the WG subscale); c) they were repeated ( 2 items from the OR subscale). Later, all items from the original scale which referred to the same concept or being generic were conceptualised in one item (e.g., 'If a wife is beaten by her husband, she should divorce him immediately' and 'A wife should move out of the house if her husband beats her'). The terminology used in the rest of the items was adapted to bring them into line with the current conception of IPV i.e. 'husband' was replaced with 'partner' or 'abuser', 'wife' by 'partner' or 'woman', 'battering' by 'beating up' or 'violence', 'get sympathy from others' by 'play the victim' and 'benefits women gain from beating' (WG subscale) by 'responsibility of the woman'. Finally, a panel of experts on gender violence examined the items carefully. This review resulted in the addition of a further nine items covering theoretical and empirical aspects of IPV which were missing from the original inventory and subsequent adaptations, such 
as the economic independence of the woman. The new instrument consisted of 22 items, grouped into three subscales. The Justifying Partner Violence subscale (JPV; six items; e. g., "Sometimes abuse of the woman helps resolve conflicts between partners") deals with general behaviours of victims and abusers which may be used to legitimise or justify IPV. The Victims Responsible for Violence subscale (VRV; nine items; e.g., "Battered women are responsible for battering, because they provoke it") deals with victim behaviours which may lead to women being blamed for IPV. Finally, the Abuser Responsible for Violence subscale (ARV; seven items; e. g., "Abusers are responsible for battering, because their intention is to intimidate and humiliate their partner") deals with abusive behaviours such as intimidation and humiliation where the aim is to ensure the submission of the victim and achieve control over her. The Appendix details all the items included in the final version of the inventory.

The Ambivalent Sexism Inventory (ASI, Glick \& Fiske, 1996) in a validated Spanish version (Expósito, Moya \& Glick, (1998) was used to measure sexist beliefs. The inventory comprises 22 items grouped into two scales: hostile sexism (HS) (e.g., "Most women fail to appreciate fully all that men do for them") and benevolent sexism (BS) (e.g., "Women should be cherished and protected by men"). Responses are given using a seven-point Likert scale ranging from 1 (totally disagree) to 7 (totally agree). Internal consistency was assessed using Cronbach's alpha coefficient, values for the hostile and benevolent sexism subscales were .87 and .84 respectively (Glick \& Fiske, 1996). In this sample, the corresponding values for the hostile and benevolent sexism subscales were .93 and .90 , respectively.

The Ambivalent Sexism towards Men Inventory (AMI, Glick \& Fiske, 1999) was used to evaluate ambivalent attitudes towards men that reinforce male dominance. The scale comprises 20 items grouped in two factors: hostile sexism (HM) (e.g., "Men act like babies when they are sick") and benevolent sexism (BM) (e.g., "Every woman ought to have a man she adores"). The response format was the same as in previous scales. Internal consistency was assessed with Cronbach's alpha and values for the hostile and benevolent sexism scales was .76 and .80 respectively (Glick \& Fiske, 1999). In our sample the corresponding values were .89 and .92 , respectively.

Socio-demographic information. Participants were asked to provide data on socio-demographic variables, namely age, gender, parental status and education level.

\section{Statistical Analysis}

Confirmatory factor analysis using the maximum likelihood estimation procedure was conducted to determine the construct validity of a three-factor model. Although exploratory factor analysis can be a very valuable instrument for exploring the structure of newly constructed scales, we chose to use a confirmatory strategy as we had a plausible hypothesis about the structure of the model (Bollen, 1989).
It was not appropriate to use $\chi^{2}$ to assess the fit of the model (because this test is very sensitive to sample size), so the evaluation was based on a combination of indices. The Root Mean Square Error of Approximation (RMSEA) was used as an index of absolute fit; values below .05 indicate a close fit, values between .05 and .08 a fair fit, and values between .08 and .10 a mediocre fit and values above .10 an unacceptably poor fit. The Normed Fit Index (NFI) and Comparative Fit Index (CFI) were used as indices of incremental fit, both range from 0 to 1 ; values between .90 and .95 indicate acceptable model fit and values greater than .95 indicating close model fit (Hu \& Bentler, 1999).

Invariance testing was conducted across groups for three increasingly restrictive models: the multiple-group baseline model, the metric invariance model and the scalar invariance model. The multiple-group baseline model assessed configural invariance across the groups used in the original model with all parameters freely estimated. The metric invariance model, which was nested within the multiple-group baseline model, added the restriction of invariant factor loadings across groups. Finally, the scalar invariance model, which was nested within the metric invariance model, added the constraint of equal item thresholds for all groups. The comparison of models was based on the changes in chi-squared, CFI and RMSEA across nested models. However, because change in chi-squared is sensitive to sample size, the major indicators of model invariance were the changes in CFI and RMSEA. We used Chen's (2007) criteria for assessing invariance, namely that when sample size is adequate $(N>300)$, $\Delta \mathrm{CFI} \leq-.01$ and $\Delta \mathrm{RMSEA} \leq-.015$ indicate that the null hypothesis of measurement invariance should not be rejected.

Descriptive statistics for all items were calculated and this was followed by analysis of the reliability of the scale. Cronbach's alpha coefficient was determined to establish the internal consistency of the subscales. In addition, as recommended by (Brown, 2015) and (Raykov \& Marcoulides, 2011), we calculated the reliability composite. To assess convergent and discriminant validity we calculated the correlations between the subscales using Pearson's correlation coefficient. Finally, differential validity was assessed by investigating differences between scores on the subscales due to sociodemographic variables (gender and age) using a MANOVA. Tests for normality were conducted with reference to skewness and kurtosis values of the observed variables. Although the items did not exhibit normal multivariate kurtosis, according to (Finch, 2005) the parametric statistic is robust even when the assumption of normality is violated, and it slightly outperforms the nonparametric statistic in terms of type I error rate and power.

AMOS 21 was used to analyze the factor structure of the scale and SPSS 19 was used to assess reliability, group differences and correlations amongst variables. 


\section{Results}

\section{Confirmatory Factor Analysis}

Figure 1 shows the path diagram for the proposed mod$\mathrm{el}$, including standardised regression coefficients and the estimated correlations between factors. The use of standardised regression coefficient values was appropriate because factor loadings were high (except for items 6, 15, 21 and 22) they are all significant $(\phi<.001)$. The correlation between the JPV and VRV subscales was high and positive (.72), which is unsurprising given the conceptual relationship between these subscales. In contrast there were negative correlations between JPV and ARV (-.18), and between VRV and ARV (-.20), indicating that high ARV scores were associated with low scores on the other two subscales. Indices of global fit indicated acceptable fit: $C F I=.952, N F I=.942$ and RMSE $A=.062$.

\section{Factorial Invariance Models}

With regard to configural invariance, without equality constraints, the fit was acceptable for gender $(C F I=.932$, RMSE $A=.049)$, indicating that the factor model was an acceptable fit to data from both men and women, although correlations between factors were higher for men than for women (see Figure 2). This model was used as the baseline with which all remaining models were compared in the process of assessing invariance. The other models (metric invariance and scalar invariance) showed acceptable fit (CFI = .930, RMSE $A=.049$ and $C F I=.925$, RMSE $A=.049$, respectively). At the metric invariance level, changes of less than .01 in CFI and less than .015 in RMSEA indicated that factor loadings were invariant across gender. The negligible changes in these indices when the additional constraint of equal item thresholds was imposed provided evidence of scalar invariance across gender (see Table 1). Parameter invariance was thus supported at both the metric and scalar levels across gender.

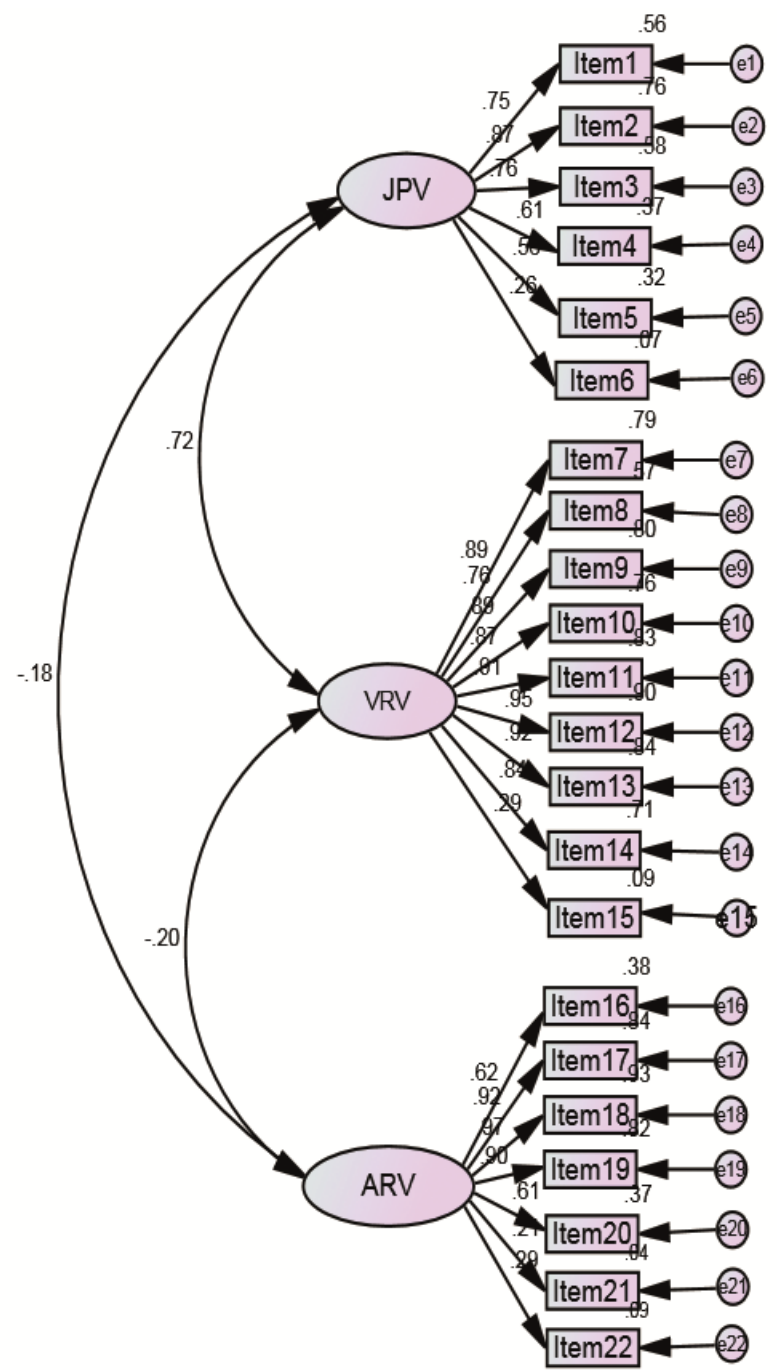

Figure 1. Confirmatory factor analysis of the Inventory of Beliefs about Intimate Partner Violence. The subscales are: JPV = Justifying Partner Violence; $\mathrm{VRV}=$ Victims Responsible for Violence $; \mathrm{ARV}=$ Abuser Responsible for Violence.

Table 1. Factorial invariance of the IBIPV across gender.

\begin{tabular}{lcccccccc}
\hline Model & $\chi^{2}$ & $d f$ & $\Delta \chi^{2}$ & $\Delta d f$ & CFI & RMSEA & $\Delta$ CFI & $\Delta$ RMSEA \\
\hline Multiple-group baseline model & 1558.7 & 412 & & & .932 & .049 & & \\
Metric invariance & 1616.9 & 431 & $58.2^{*}$ & 19 & .930 & .049 & .002 & .000 \\
Scalar invariance & 1721.9 & 453 & $105^{*}$ & 22 & .925 & .049 & .005 & .000 \\
\hline
\end{tabular}




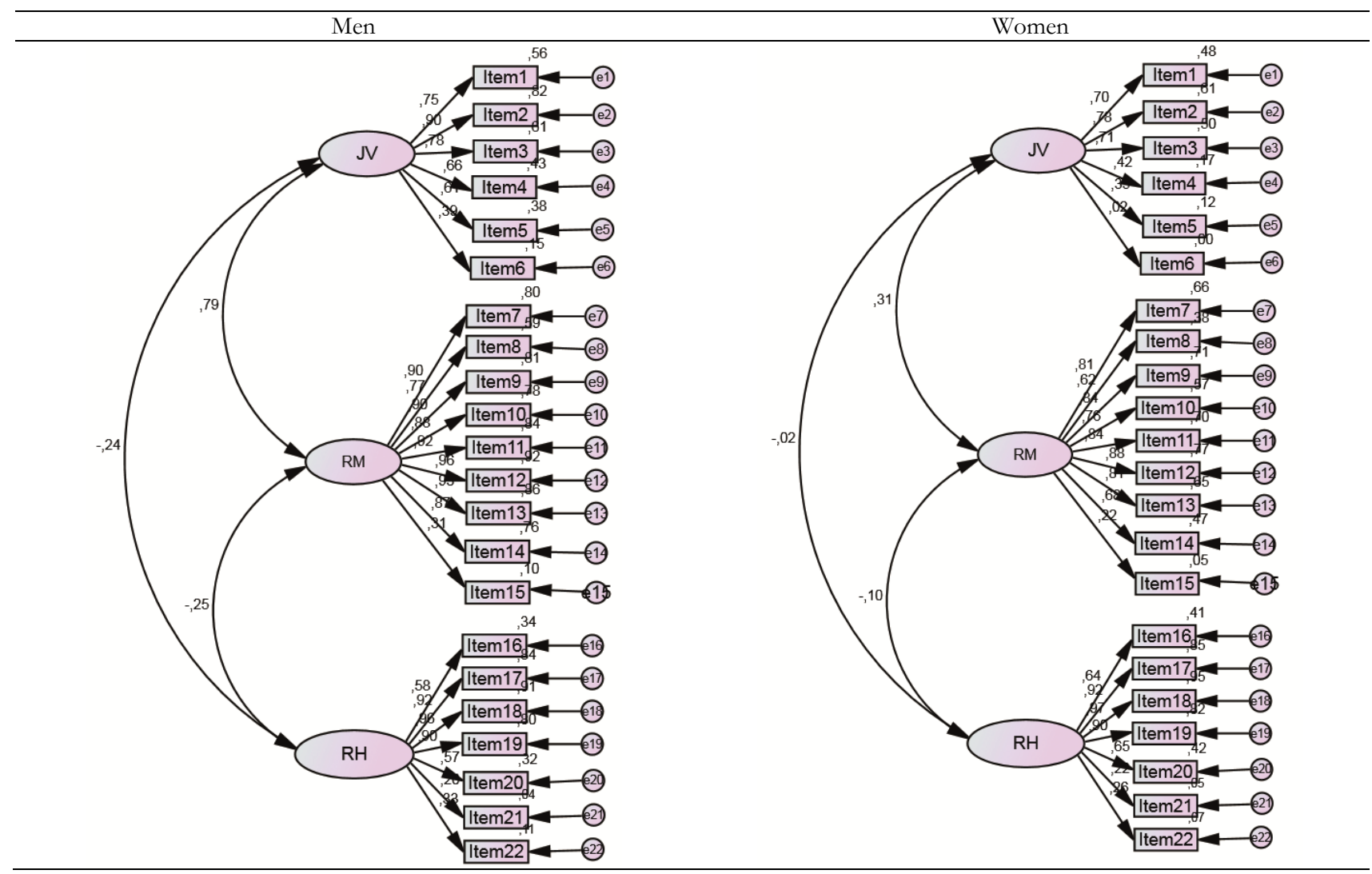

Figure 2. Multiple-group baseline model of the Inventory of Beliefs about Intimate Partner Violence. The subscales are: JPV = Justifying Partner Violence; $\mathrm{VRV}=$ Victims Responsible for Violence; ARV = Abuser Responsible for Violence.

\section{Reliability}

Tables 2 and 3 present means, standard deviations and discrimination indices for items, as well as alpha values and the composite reliability for the three factors underlying the scale (JPV, VRV and ARV). Item-total correlations were within the acceptable range except in the case of items 6,15 and 21. The internal consistency of the VRV and ARV subscales was high (.93 and .84 respectively) and that of the JPV subscale was moderate (.71). Estimates of the reliability of the three subscales were slightly higher using the composite reliability procedure instead of the alpha coefficient, as the alpha statistic underestimates reliability in ordinal data (Bentler, 2009). Given that the threshold of acceptability for composite reliability is .70 , the values for the three subscales (.81, .95 and .85 ) suggest an acceptable level of reliability.

Table 3. Means, standard deviations, Cronbach's alpha and composite reliability (CR) for the subscales of the Inventory of Beliefs about Intimate Partner Violence.

\begin{tabular}{lcccc}
\hline Subscale & $M$ & $S D$ & $\alpha$ & CR \\
\hline Justifying Partner Violence & 1.40 & 1.25 & .71 & .81 \\
Victims Responsible for Violence & 1.42 & 1.15 & .93 & .95 \\
Abuser Responsible for Violence & 4.99 & 1.96 & .84 & .85 \\
\hline
\end{tabular}

Table 2. Descriptive statistics, discrimination indices and values of Cronbach's alpha and composite reliability (CR) for IBIPV items.

\begin{tabular}{|c|c|c|c|c|}
\hline Subscale & $\alpha$ & CR $M$ & $S D$ & $r_{i x}$ \\
\hline Justifying Partner Violence & .71 & .811 .40 & 1.25 & \\
\hline Item 1 & & 1.30 & 1.13 & .56 \\
\hline Item 2 & & 1.21 & 0.90 & .68 \\
\hline Item 3 & & 1.21 & 0.90 & .53 \\
\hline Item 4 & & 1.38 & 1.12 & .50 \\
\hline Item 5 & & 1.47 & 1.32 & .46 \\
\hline Item 6 & & 1.83 & 1.85 & .21 \\
\hline Victims Responsible for Violence & .93 & .951 .42 & 1.15 & \\
\hline Item 7 & & 1.28 & 1.00 & .86 \\
\hline Item 8 & & 1.50 & 1.24 & .72 \\
\hline Item 9 & & 1.27 & 0.97 & .86 \\
\hline Item 10 & & 1.36 & 1.09 & .83 \\
\hline Item 11 & & 1.33 & 1.05 & .87 \\
\hline Item 12 & & 1.36 & 1.08 & .91 \\
\hline Item 13 & & 1.33 & 1.07 & .87 \\
\hline Item 14 & & 1.30 & 1.02 & .82 \\
\hline Item 15 & & 2.03 & 1.68 & .28 \\
\hline Abuser Responsible for Violence & .84 & .854 .99 & 1.96 & \\
\hline Item 16 & & 3.96 & 2.13 & .58 \\
\hline Item 17 & & 5.03 & 1.97 & .83 \\
\hline Item 18 & & 5.12 & 1.96 & .84 \\
\hline Item 19 & & 5.09 & 1.99 & .82 \\
\hline Item 20 & & 5.83 & 1.85 & .59 \\
\hline Item 21 & & 5.10 & 1.82 & .22 \\
\hline Item 22 & & 4.86 & 1.98 & .33 \\
\hline
\end{tabular}




\section{Relationships with Other Variables}

To obtain evidence about the convergent and divergent validity of the scale we examined relationships between scores on the IBIPV subscales and AMI and ASI subscales about which we had made theoretically derived predictions. As shown in Table 4 both the JPV and VRV subscales were positively correlated both factors of the AMI and ASI.

It is worth pointing out that these correlations were stronger for men (lower diagonal in Table 2) than for women (upper diagonal). Although all the correlations were significant (the sample size was large) the effect size was larger for men, inasmuch as correlations ranged from moderate to large (.35 to .53). For women, the effect size ranged from low to moderate (.16 to .28). These relationships with related, established scales provided evidence of the convergent validity of the IBIPV.

As expected, the correlations between the ARV subscale and the AMI and ASI subscales were very close to zero in both men and women, providing evidence of the divergent validity of this subscale.

Table 4. Correlations between the IBIPV subscales and factors of two sexism scales in men (lower diagonal) and in women (upper diagonal).

\begin{tabular}{|c|c|c|c|c|c|c|c|}
\hline & JPV & VRV & ARV & $\mathrm{HM}$ & BM & HS & BS \\
\hline$\overline{\mathrm{JPV}}$ & 1 & .35* & $-.13^{*}$ & $.19 *$ & $.28^{*}$ & $.22 *$ & $.23^{*}$ \\
\hline VRV & $.75^{*}$ & 1 & $-.19 *$ & $.20^{*}$ & $.20^{*}$ & $.16^{*}$ & $.22 *$ \\
\hline ARV & $-.27^{*}$ & $-.29 *$ & 1 & $.11 *$ & .01 & -.01 & .05 \\
\hline HM & $.44^{*}$ & $.42^{*}$ & -.06 & 1 & $.60^{*}$ & $.52^{*}$ & $.64 *$ \\
\hline $\mathrm{BM}$ & $.53 *$ & $.51^{*}$ & -.09 & $.72^{*}$ & 1 & $.57 *$ & $.75^{*}$ \\
\hline HS & $.37 *$ & $.37 *$ & $-.11^{*}$ & $.60 *$ & $.73^{*}$ & 1 & $.58^{*}$ \\
\hline BS & $.36^{*}$ & $.35 *$ & .01 & $.65^{*}$ & $.78^{*}$ & $.67^{*}$ & 1 \\
\hline
\end{tabular}

\section{Differential Validity}

Gender differences. A multivariate analysis of variance (MANOVA) was used to evaluate gender differences in scores on the three subscales to provide evidence of differential validity. Statistically significant gender differences were found, $F(3,1162)=23.07, p<.01, \eta^{2}=.06$. In addition, a series of ANOVAs revealed statistically significant gender differences with respect to the JPV subscale $F(1,1164)=$ 49.97, $p<.01, \eta^{2}=.04$, the VRV subscale $=F(1,1164)=$ $52.45, p<.01, \eta^{2}=.04$ and the ARV subscales $F(1,1164)=$ 20.91, $p<.01, \eta^{2}=.02$; however, these were small effects, as is common in this type of study. More specifically, men obtained higher scores than women on the JPV (1.63 vs. 1.28) and VRV (1.61 vs. 1.23) subscales, whereas for the ARV subscale the reverse pattern prevailed (4.81 vs. 5.18).

Age differences. Three age ranges were used in the analysis of age differences (18 to 35 years; 36 to 50 years; over 50 years). There were significant age differences in scores on the JPV subscale $F(1,1047)=9.18, p<.01, \eta^{2}=$ .03 and VRV subscale $F(1,1047)=5.45, p<.01, \eta^{2}=.01$ as well as significant interactions between age and gender with respect to JPV score $F(1,1047)=5.43, p<.01, \eta^{2}=.01$ and VRV score $F(1,1047)=3.60, p<.05, \eta^{2}=.01$. As shown in Figures 3 and 4 , men scored higher than women on both subscales; however, women's scores were fairly stable across the age ranges whereas men's scores were higher in the over50 age category. Figure 5 shows that there were no significant age differences in ARV subscale scores, $F(1,1047)=$ $0.01, p>.05, \eta^{2}=.00$.

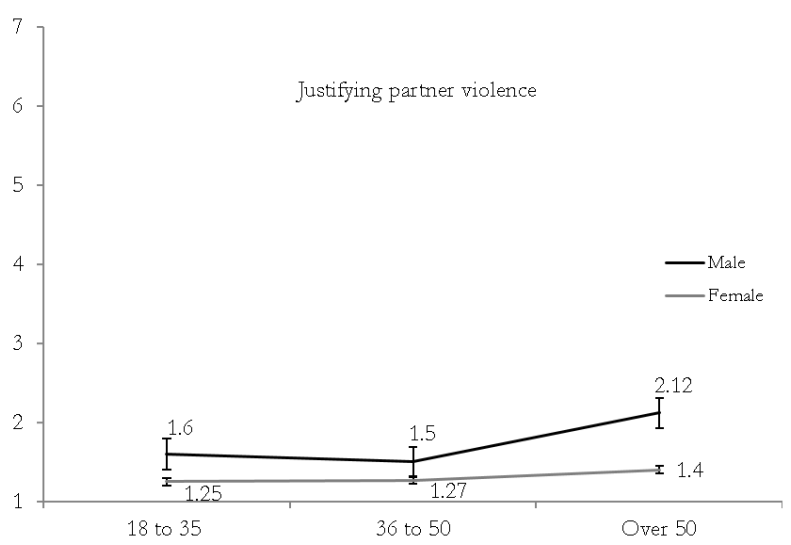

Figure 3. Mean scores for men and women on the Justifying partner violence subscale across age categories.

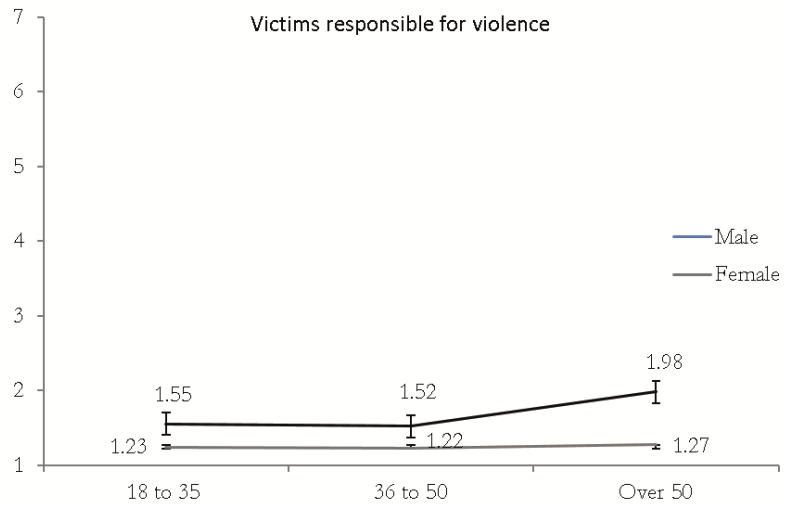

Figure 4. Mean scores for men and women on the Victim responsible for violence subscale across age categories.

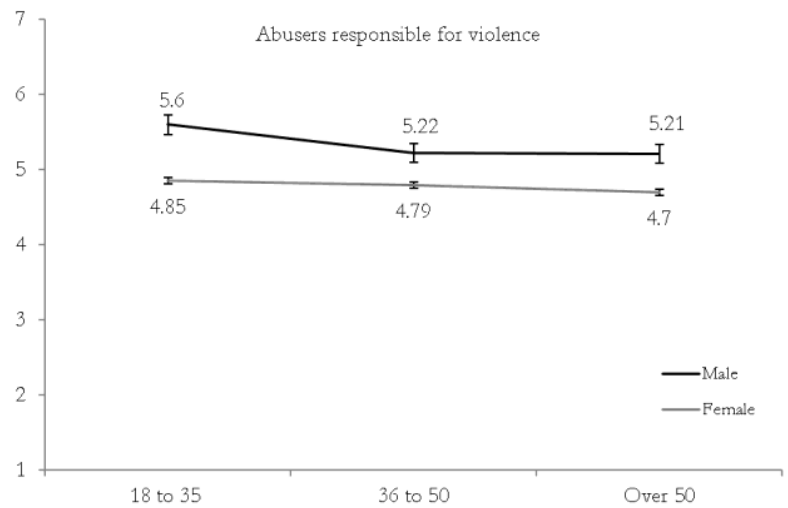

Figure 5. Mean scores for men and women on the Abusers responsible for violence subscale across age categories. 


\section{Discussion}

The aim of this study was to develop and validate a new scale, the Inventory of Beliefs about Intimate Partner Violence (IBIPV), based on the IBWB (Saunders et al., 1987). In general, the results from our sample of 1169 Spanish participants show that new scale has factorial validity, internal consistency, convergent, divergent and differential validity.

As regards factorial validity, robust fit indices indicated that a three-factor model was an adequate fit to the data, confirming the underlying structure of the scale. The first factor (Justifying Partner Violence, JPV) reflects the attitude that IPV is generally justified (e.g. Occasional violence towards the woman can help to maintain a relationship). This subscale is a shortened form of the corresponding subscale of the IBWB, but had higher internal consistency than the original (Saunders et al., (1987). The second factor (Victims Responsible for Violence, VRV) encompassed victim-blaming attributions of responsibility for IPV, which are very widespread amongst the general population; it included items attributing IPV to victims' feminist beliefs and provocative behaviour (e.g., "Battered women are responsible for battering, because they provoke it"). In fact, research has confirmed that people attribute IPV to the provocative personality of the victims (e.g. Gracia \& Tomás, 2014; Lila et al., 2014). The third factor (Abuser Responsible for Violence, ARV), retained items from the IBWB (Saunders et al., 1987) which attributed responsibility directly or indirectly to the victims (e.g. "The best way to combat violence against women is to arrest the perpetrators"), but also included items describing perpetrator behaviours aimed at controlling victims or coercing them into submission (e.g., "Abusers are responsible for battering, because their intention is to restrict their partner's freedom"). This is an important issue, inasmuch as psychological abuse is the most prevalent form of IPV (Rathus \& Feindler, 2004).

The factor loading of the items was also acceptable; loadings were high, except in the case of items 6, 15, 21 and 22. Internal consistency by confirmatory analyses was always above .70 , higher than for the corresponding IBWB subscale (Saunders et al., 1987). Alpha coefficient values and composite reliability indices were acceptable. The mean scores for the JPV and VRV subscales were below the midpoint of the scale, but the mean score for the ARV subscale was above the midpoint, which is quite common in this type of study (e.g. Haj-Yahia, 2003). Moreover, the correlations among the subscales followed the pattern found in previous research (e.g. Gracia et al., 2015); JPV was positively related to VRV and negatively related to ARV, whilst VRV and ARV were negatively correlated.

Our results also provided strong evidence of measurement invariance, an issue that is frequently overlooked. In particular, the data confirmed the configural, metric and scalar invariance of the scale across gender, suggesting that the IBIPV provides an equivalent assessment of attitudes towards violence against women in both genders. Nevertheless, it is worth noting that the correlations between constructs were higher for men than for women. This is not surprising as research has shown that women tend to express stronger disapproval of wife beating than men (Gracia et al., 2015; Sakalli, 2001; Valor-Segura et al., 2011) and also attribute less blame to the victim and more to the perpetrator (Strömwall, Landström, \& Alfredsson, 2014) .

The pattern of correlations between subscales scores and sexist beliefs provided evidence of the IBIPV's convergent and divergent validity. Consistent with other research (Forbes, Jobe, White, Bloesch, \& Adams-Curtis, 2005; ValorSegura et al., 2011), the JPV and VRV subscales were positively and adequately correlated with HS and BS. We extended knowledge in this area by demonstrating that the JRV and VRV subscales were also positively correlated with HM and BM. Furthermore, the magnitude of the correlations between these subscales and HM, BM, HS, and BS was significantly higher for men than for women, particularly with respect to $\mathrm{BM}$. This is not surprising given that BM reflects a belief that women should cater the needs of men at home (Glick et al., 2004).

Evidence for the divergent validity of the new scale came from the near-zero correlations between the ARV subscale and the hostile and benevolent factors of AMI and ASI. An important finding was that men high in HS tended to exonerate abusers; perhaps as a way of legitimising violence against women who do not fulfil traditional gender roles (Valor-Segura et al., 2011). In contrast, women high in HM put more blame on the abuser, perhaps in reaction to male dominance.

We found that there was significant age- and genderrelated differences in scores. Men scored higher than women on the JPV and VRV subscales, whereas women scored higher on the ARV subscale. These results agree with other research indicating that women tend to attribute less responsibility to the victims of IPV and more blame to the perpetrators than men (Alfredsson et al., 2016; Valor-Segura et al., 2011). Our results also revealed that women's beliefs about justification of IPV and victims' responsibility for IPV were similar in all age groups whereas men tended to take a more tolerant approach to IPV and be more lenient towards the perpetrators if they were over 50 years old. As in other studies, our results indicate that older men continue to accept IPV as a normal part of a close relationship, whereas younger men distanced themselves from these patriarchal beliefs (Worden \& Carlson, 2005), perhaps because of the diverse social interventions carried out in the last few years in educational contexts and more generally via mass media.

Finally, it is important to highlight the three important contributions our study makes to the field. First, the IBIPV takes account of recent theoretical and empirical advances in understanding of IPV such as the recognition of the importance of psychological abuse and the relevance of the victim's economic dependence or independence. Second, suitable methodological resources are used to collect validity evidence for the scoring scale. Third, reducing the number of 
subscales to three has produced a more accurate measure of attitudes towards IPV. The good psychometric properties of the new scale mean that it has potential as a tool for measuring attitudes to IPV as part of efforts to ensure the effectiveness of interventions designed to reduce societal tolerance of IPV. Further research using the IBIPV alongside instruments designed to measure variables such as attitudes to traditional gender roles would provide more evidence on the validity of the instrument.

Although this study makes several important contributions to the field it is not without limitations. These include

\section{References}

Alfredsson, H., Ask, K., \& Borgstede, C. (2016). Beliefs about intimate partner violence: A survey of the Swedish general public. Scandinavian Journal of Psychology, 57, 57-64. doi:10.1111/sjop.12254

American Psychological Association. (1996). Violence and the family: Report of the APA presidential task force. Washington, DC: American Psychological Association.

Balluerka, N., Gorostiaga, A., Alonso-Arbiol, I., \& Haranburu, M. (2007). La adaptación de instrumentos de medida de unas culturas a otras: Una perspectiva práctica. Psicothema, 19(1), 124-133.

Bentler, P. M. (2009). Alpha, dimension-free, and model-based internal consistency reliability. Psychometrika, 74, 137-143. doi:10.1007/s11336008-9100-1

Berkel, L. A., Vandiver, B. J., \& Bahner, A. D. (2004). Gender role attitudes, religion, and spirituality as predictors of domestic violence attitudes in white college students. Journal of College Student Development, 45, 119-133. doi:10.1353/csd.2004.0019

Bollen, K. A. (1989). A new incremental fit index for general structural equation models. Sociological Methods \& Research, 17, 303-316. doi:10.1177/0049124189017003004

Brown, T. A. (2015). Confirmatory factor analysis for applied research. New York, NY: Guilford Press.

Buesa, S., \& Calvete, E. (2011). Adaptación de la escala de abuso psicológico sutil y manifiesto a las mujeres en muestra clínica y de la comunidad, 27, 774-782.

Cantera, L. M., \& Blanch, J. M. (2010). Percepción social de la violencia en la pareja desde los estereotipos de género. Intervención Psicosocial, 19(2), 121-127.

Capezza, N. M., \& Arriaga, X. B. (2008). Factors associated with acceptance of psychological aggression against women. Violence Against Women, 14, 612-633. doi: 10.1177/1077801208319004

Chen, F. F. (2007). Sensitivity of goodness of fit indexes to lack of measurement invariance. Structural Equation Modeling, 14(3), 464-504.

Craig, M. E., Robyak, J., Torosian, E. J., \& Hummer, J. (2006). A study of male veterans' beliefs toward domestic violence in a batterers intervention program. Journal of Interpersonal Violence, 21, 1111-1128. doi:10.1177/0886260506290418

Expósito, F., Moya, M. C., \& Glick, P. (1998). Sexismo ambivalente: Medición y correlatos. Revista de Psicología Social, 13, 159-169. doi:10.1174/021347498760350641

Expósito, F., \& Ruiz, S. (2010). Reeducación de maltratadores: Una experiencia de intervención desde la perspectiva de género. Intervención Psicosocial, 19(2), 145-151.

Ferrer, V. A., Bosch, E., Ramis, M. d. C., \& Navarro, C. (2006). Las creencias y actitudes sobre la violencia contra las mujeres en la pareja: Determinantes sociodemográficos, familiares y formativos. Anales de Psicología, 22(2), 251-259.

Finch, H. (2005). Comparison of the performance of nonparametric and parametric MANOVA test statistics when assumptions are violated. Methodology, 1, 27-38. doi:1027/1614-1881.1.1.27

Flood, M., \& Pease, B. (2009). Factors influencing attitudes to violence against women. Trauma, Violence \& Abuse, 10, 125-142. doi:10.1177/1524838009334131 the use of an incidental sample, which prevent relevant normative information from being to offer. For example, population variance in certain variables was not adequately represented in the sample, that is to say people with higher education were over-represented. Further research based on probabilistic samples would be useful. Besides, the results of the questionnaire show another limitation which makes it difficult to obtain reliability test-retest estimates in the current study. This can also guide future studies regarding psychometric characteristics of this scale.
Forbes, G. B., Jobe, R. L., White, K. B., Bloesch, E., \& Adams-Curtis, L. E. (2005). Perceptions of dating violence following a sexual or nonsexual betrayal of trust: Effects of gender, sexism, acceptance of rape myths, and vengeance motivation. Sex Roles, 52, 165-173. doi:10.1007/s11199005-1292-6

Glick, P., \& Fiske, S. T. (1996). The ambivalent sexism inventory: Differentiating hostile and benevolent sexism. Journal of Personality and Social Psychology, 70, 491-512. doi:10.1037/0022-3514.70.3.491

Glick, P., \& Fiske, S. T. (1999). The ambivalence toward men inventory. Psychology of Women Quarterly, 23, 519-536. doi:10.1111/j.14716402.1999.tb00379.x

Glick, P., Lameiras, M., Fiske, S. T., Eckes, T., Masser, B., Volpato, C., . . Sakalli-Uğurlu, N. (2004). Bad but bold: Ambivalent attitudes toward men predict gender inequality in 16 nations. Journal of Personality and Social Psychology, 86, 713. doi:10.1037/0022-3514.86.5.713

Glick, P., Sakalli-Ugurlu, N., Ferreira, M. C., \& de Souza, M. A. (2002). Ambivalent sexism and attitudes toward wife abuse in Turkey and Brazil. Psychology of Women Quarterly, 26, 292-297. doi:10.1111/14716402.t01-1-00068

Gracia, E. (2014). Intimate partner violence against women and victimblaming attitudes among Europeans. Bulletin of the World Health Organization, 92, 380-381. doi:10.2471/BLT.13.131391

Gracia, E., García, F., \& Lila, M. (2009). Public responses to intimate partner violence against women: The influence of perceived severity and personal responsibility. The Spanish Journal of Psychology, 12, 648-656. doi:10.1017/S1138741600002018

Gracia, E., García, F., \& Lila, M. (2014). Male police officers' law enforcement preferences in cases of intimate partner violence versus nonintimate interpersonal violence: Do sexist attitudes and empathy matter? Criminal Justice and Behavior, 41, 1195-1213. doi: $10.1177 / 0093854814541655$

Gracia, E., \& Herrero, J. (2006a). Public attitudes toward reporting partner violence against women and reporting behavior. Journal of Marriage and Family, 68, 759-768. doi:10.1111/j.1741-3737.2006.00288.x

Gracia, E., Rodriguez, C. M., \& Lila, M. (2015). Preliminary evaluation of an analog procedure to assess acceptability of intimate partner violence against women: The partner violence acceptability movie task. Frontiers in Psychology, Published online. doi: $10.3389 \% 2 F f p s y g .2015 .01567$

Gracia, E., \& Tomás, J. M. (2014). Correlates of victim-blaming attitudes regarding partner violence against women among the Spanish general population. Violence Against Women, Published online. doi:10.1177/1077801213520577

Gracia, E., \& Herrero, J. (2006b). Acceptability of domestic violence against women in the European Union: A multilevel analysis. Journal of Epidemiology and Community Health, 60, 123-129. doi:10.1136/jech.2005.036533

Haj-Yahia, M. M. (2003). Beliefs about wife beating among Arab men from Israel: The influence of their patriarchal ideology. Journal of Family Violence, 18(4), 193-206. doi:10.1023/A:1024012229984

Haj-Yahia, M. M., \& de Zoysa, P. (2007). Beliefs of Sri Lankan medical students about wife beating. Journal of Interpersonal Violence, 22, 26-49. doi:10.1177/0886260506294995 
Hu, L., \& Bentler, P. M. (1999). Cutoff criteria for fit indexes in covariance structure analysis: Conventional criteria versus new alternatives. Structural Equation Modeling: A Multidisciplinary Journal, 6, 1-55. doi:10.1080/10705519909540118

Jackson, D. N., Guthrie, G. M., Astilla, E., \& Elwood, B. (1983). The crosscultural generalizability of personality construct measures. In J. W. Berry, \& S. H. Irvine (Eds.), Human assessment and cultural factors (NATO Conference Series ed., pp. 365-375). New York, NY: Springer.

Langhinrichsen-Rohling, J., Shlien-Dellinger, R. K., Huss, M. T., \& Kramer, V. L. (2004). Attributions about perpetrators and victims of interpersonal abuse: Results from an analogue study. Journal of Interpersonal Violence, 19(4), 484-498. doi:10.1177/0886260503262084

Lila, M., Oliver, A., Catalá-Miñana, A., Galiana, L., \& Gracia, E. (2014). The intimate partner violence responsibility attribution scale (IPVRAS). The European Journal of Psychology Applied to Legal Context, 6, 29-36. doi:10.5093/ejpalc2014a4

Maiuro, R. D. (2004). Psychological abuse in violent domestic relations. New York, NY: Springer Publishing Company.

Morgan, D. L., Krueger, R. A., \& King, J. A. (1998). Moderating focus groups. Thousand Oaks, CA: Sage.

Organización de Naciones Unidas, ONU. (2006). Estudio a fondo sobre todas las formas de violencia contra la mujer. Nueva York, NY: Naciones Unidas.

Organización Mundial de la Salud (OMS). (2005). Estudio multi-país de la OMS sobre salud de la mujer y violencia doméstica. primeros resultados sobre prevalencia, eventos relativos a la salud y respuestas de las mujeres a dicha violencia. Ginebra: OMS

Peters, J. (2008). Measuring myths about domestic violence: Development and initial validation of the domestic violence myth acceptance scale. Journal of Aggression, Maltreatment \& Trauma, 16, 1-21. doi:10.1080/10926770801917780

Pueyo, A. A., López, S., \& Álvarez, E. (2008). Valoración del riesgo de violencia contra la pareja por medio de la SARA. Papeles del Psicólogo, 29(1), 107-122.

Rathus, J. H., \& Feindler, E. L. (2004). Assessment of partner violence: A handbook for researchers and practitioners. Washington, DC: American Psychological Association.

Raykov, T., \& Marcoulides, G. A. (2011). Introduction to psychometric theory. New York, NY: Routledge, Taylor \& Francis Group.

Sakalli, N. (2001). Beliefs about wife beating among Turkish college students: The effects of patriarchy, sexism, and sex differences. Sex Roles, 44, 599-610. doi:10.1023/A:1012295109711
Saunders, D. G., Lynch, A. B., Grayson, M., \& Linz, D. (1987). The inventory of beliefs about wife beating: The construction and initial validation of a measure of beliefs and attitudes. Violence and Victims, 2(1), 3957.

Stith, S. M., Smith, D. B., Penn, C. E., Ward, D. B., \& Tritt, D. (2004). Intimate partner physical abuse perpetration and victimization risk factors: A meta-analytic review. Aggression and Violent Behavior, 10, 65-98. doi:10.1016/j.avb.2003.09.001

Straus, M. A., Hamby, S. L., Boney-McCoy, S., \& Sugarman, D. B. (1996). The revised conflict tactics scales (CTS2) development and preliminary psychometric data. Journal of Family Issues, 17, 283-316. doi:10.1177/019251396017003001

Strömwall, L. A., Landström, S., \& Alfredsson, H. (2014). Perpetrator characteristics and blame attributions in a stranger rape situation. The European Journal of Psychology Applied to Legal Context, 6, 63-67. doi:10.1016/j.ejpal.2014.06.002

Valor-Segura, I., Expósito, F., \& Moya, M. (2008). Atribución del comportamiento del agresor y consejo a la víctima en un caso de violencia doméstica. Revista De Psicología Social, 23, 171-180. doi:10.1174/021347408784135896

Valor-Segura, I., Expósito, F., \& Moya, M. (2011). Victim blaming and exoneration of the perpetrator in domestic violence: The role of beliefs in a just world and ambivalent sexism. The Spanish Journal of Psychology, 14 195-206. doi:10.5209/rev_SJOP.2011.v14.n1.17.

Waltermaurer, E. (2012). Public justification of intimate partner violence: a review of the literature. Trauma \& Violence Abuse, 13, 167-175. doi:10.1177/1524838012447699

West, A., \& Wandrei, M. L. (2002). Intimate partner violence a model for predicting interventions by informal helpers. Journal of Interpersonal Violence, 17, 972-986. doi:10.1177/0886260502017009004

Worden, A. P., \& Carlson, B. E. (2005). Attitudes and beliefs about domestic violence: Results of a public opinion survey II. beliefs about causes. Journal of Interpersonal Violence, 20, 1219-1243. doi:10.1177/0886260505278531

Yamawaki, N., Ochoa-Shipp, M., Pulsipher, C., Harlos, A., \& Swindler, S. (2012). Perceptions of domestic violence: The effects of domestic violence myths, victim's relationship with her abuser, and the decision to return to her abuser. Journal of Interpersonal Violence, 27, 3195-3212. doi: $10.1177 / 0886260512441253$

(Article received: 17-07-2015; revised: 10-03-2016; accepted: 16-08-2016) 


\section{Appendix}

\section{Inventory of Beliefs about Intimate Partner Violence (IBIPV)}

Justifying partner violence (JPV)

Sometimes men are justified in beating up their partner ${ }^{[1]}$

Occasional violence towards the woman can help maintain a relationship [1]

Sometimes abuse of the woman helps resolve conflicts between partners [2]

Violent episodes are the woman's fault [1]

Women could avoid being beaten up if they knew when to stop talking [1]

Even though men's masculinity is threatened when their partner points out their weak points, men don't have the right to beat up their partners [1]

Victims responsible for violence (VRV)

Battered women are responsible for their abuse, ...

..., because they intended it to happen [1]

..., because they should have foreseen it would happen [1]

..., because they provoke violence to get attention from men ${ }^{[1]}$

..., because of the way they behave in the weeks leading up to it ${ }^{1]}$

$\ldots$, because what they really want is to play the victim [1]

..., because they provoke it [2]

..., because of their feminist beliefs [2]

..., because they are economically independent ${ }^{[2]}$

Battered women should separate from their partners immediately [1]

Abusers responsible for violence (ARV)

Abusers are responsible for the abuse, ...

..., because they intended to behave that way from the beginning [1]

..., because they do it to impose their will [2]

..., because their intention is to restrict their partner's freedom ${ }^{[2]}$

..., because their intention is to intimidate and humiliate their partner ${ }^{[2]}$

..., because their behaviour is an attack on their partner's dignity [2]

The best way to combat violence against women is to force the abuser to attend couple counselling [2]

The best way to combat violence against women is to arrest the perpetrators [1]

Note. ${ }^{[1]}$ Item taken from the original scale (Saunders et al. 1987). ${ }^{[2]}$ Item developed specifically for the new scale. * Responses were given using a Likert scale ranging from 1 (totally disagree) to 7 (totally agree). 